\title{
Chronic nerve health following implantation of femoral nerve cuff electrodes
}

Max J. Freeberg ${ }^{1,2^{*}}$ (D), Gilles C. J. Pinault2,3,4 Dustin J. Tyler ${ }^{1,2}$, Ronald J. Triolo ${ }^{1,2,4}$ and Rahila Ansari ${ }^{2,4,5}$

\begin{abstract}
Background: Peripheral nerve stimulation with implanted nerve cuff electrodes can restore standing, stepping and other functions to individuals with spinal cord injury $(\mathrm{SCl})$. We performed the first study to evaluate the clinical electrodiagnostic changes due to electrode implantation acutely, chronic presence on the nerve peri- and postoperatively, and long-term delivery of electrical stimulation.
\end{abstract}

Methods: A man with bilateral lower extremity paralysis secondary to cervical SCI sustained 5 years prior to enrollment received an implanted standing neuroprosthesis including composite flat interface nerve electrodes (CFINEs) electrodes implanted around the proximal femoral nerves near the inguinal ligaments. Electromyography quantified neurophysiology preoperatively, intraoperatively, and through 1 year postoperatively. Stimulation charge thresholds, evoked knee extension moments, and weight distribution during standing quantified neuroprosthesis function over the same interval.

Results: Femoral compound motor unit action potentials increased 31\% in amplitude and 34\% in area while evoked knee extension moments increased significantly $(p<0.01)$ by $79 \%$ over 1 year of rehabilitation with standing and quadriceps exercises. Charge thresholds were low and stable, averaging $19.7 \mathrm{nC} \pm 6.2$ (SEM). Changes in saphenous nerve action potentials and needle electromyography suggested minor nerve irritation perioperatively.

Conclusions: This is the first human trial reporting acute and chronic neurophysiologic changes due to application of and stimulation through nerve cuff electrodes. Electrodiagnostics indicated preserved nerve health with strengthened responses following stimulated exercise. Temporary electrodiagnostic changes suggest minor nerve irritation only intra- and peri-operatively, not continuing chronically nor impacting function. These outcomes follow implantation of a neuroprosthesis enabling standing and demonstrate the ability to safely implant electrodes on the proximal femoral nerve close to the inguinal ligament. We demonstrate the electrodiagnostic findings that can be expected from implanting nerve cuff electrodes and their time-course for resolution, potentially applicable to prostheses modulating other peripheral nerves and functions.

Trial registration: ClinicalTrials.gov NCT01923662, retrospectively registered August 15, 2013.

Keywords: Chronic nerve health, Electromyography, Rehabilitation, peripheral nerve cuff electrodes, Electrodiagnostics and neuromuscular diseases, Electrical stimulation, Spinal cord injury

\footnotetext{
* Correspondence: mxf218@case.edu

${ }^{1}$ Department of Biomedical Engineering, Case Western Reserve University,

Cleveland, $\mathrm{OH}, \mathrm{USA}$

${ }^{2}$ Advanced Platform Technology (APT) Center, Cleveland, OH, USA

Full list of author information is available at the end of the article
}

\section{$\triangle B M C$}

(c) The Author(s). 2020 Open Access This article is licensed under a Creative Commons Attribution 4.0 International License, which permits use, sharing, adaptation, distribution and reproduction in any medium or format, as long as you give appropriate credit to the original author(s) and the source, provide a link to the Creative Commons licence, and indicate if changes were made. The images or other third party material in this article are included in the article's Creative Commons licence, unless indicated otherwise in a credit line to the material. If material is not included in the article's Creative Commons licence and your intended use is not permitted by statutory regulation or exceeds the permitted use, you will need to obtain permission directly from the copyright holder. To view a copy of this licence, visit http://creativecommons.org/licenses/by/4.0/ The Creative Commons Public Domain Dedication waiver (http://creativecommons.org/publicdomain/zero/1.0/) applies to the data made available in this article, unless otherwise stated in a credit line to the data. 


\section{Background}

Electrical stimulation of peripheral nerves can restore or modulate functions of the somatic and autonomic peripheral nervous system. Somatic interfaces can modulate several functions ranging from prostheses restoring movement following central nervous system injury [1-3] to those restoring sensation and controlling prostheses following extremity amputation [4-7]. Surgically implanted neuroprostheses can restore function to individuals with spinal cord injury (SCI) by eliciting contractions of the otherwise paralyzed muscles via electrical stimulation of peripheral motor nerves [1, 8-12]. These systems can restore numerous functions-including walking, cycling, and bladder function-by interfacing with the nervous system at the spinal cord [1317], at the anterior roots [18-22], at peripheral nerves $[1,3]$, and at the points of innervation in muscles $[3,12$, 23 ], or some combination thereof.

Nerve-based electrodes have advantages over other electrode designs [24, 25], including robust, stable recruitment, and improved functional outcomes [1, 26]. These electrodes may be penetrating or non-penetrating. While penetrating electrodes offer the potential of higher selectivity [27-29], non-penetrating nerve cuff electrodes (NCEs) on nerves in the upper [2, 4, 5, 30] and lower $[3,26,31-35]$ extremities have been operational and stable for more than 11 years postimplantation [31] in terms of stimulation threshold and functional output over time $[2,26]$. To date, the effects of both implantation and chronic use of NCEs on neurophysiology and muscle innervation have not been examined with established clinical measures, including both nerve conduction studies (NCS) and needle electromyography (EMG). This dearth of neurophysiological outcomes and lack of baseline electrodiagnostic changes in well-functioning neuroprostheses make it difficult to gauge the impact of novel NCE designs, implant locations, surgical approaches, and rehabilitation paradigms on nerve health.

As NCE designs include higher contact densities [36] they are able to achieve sufficient selectivity to be implanted on proximal nerve trunks [37]. The flat interface nerve electrode gently reshapes peripheral nerves to increase accessible surface area for multiple contacts, allowing for better access to distinct populations of nerve fascicles [36]. The 8-contact FINE is sufficiently selective to separate hip flexors from knee extensors [37] when implanted proximal to the first branch off the femoral nerve, approximately $1-2 \mathrm{~cm}$ distal to the inguinal ligament [38]. The inguinal ligament is a possible site of femoral nerve entrapments, especially during hip flexion and rotation [39-42]. The composite flat interface

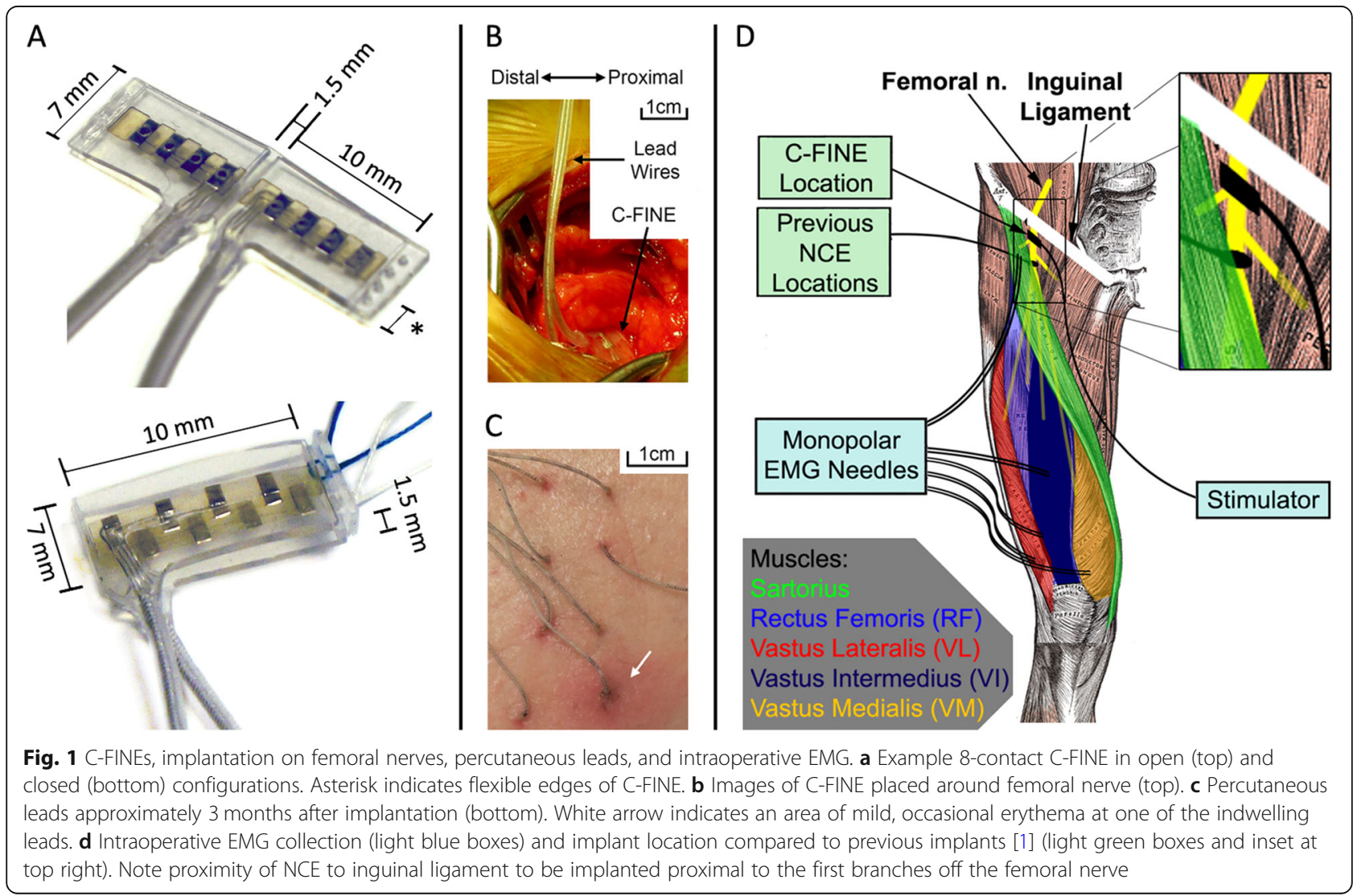


electrode (C-FINE, Fig. 1a) [43] was developed to be a small and flexible reshaping NCE to accommodate the stresses and strains in such locations. Yet, the acute and chronic consequences of the C-FINE on neurophysiology, especially in novel implant locations (e.g., close to the inguinal ligament) have not been established.

Numerous elements of a neuroprosthesis, such as NCE design, lead routing, implant location, and surgical approaches, may affect nerve health. Neurophysiological and electrodiagnostic changes can also be caused by intraoperative nerve manipulation, perioperative positioning [41] and edema [44], and nerve traction. These changes can range from temporary demyelination and neurapraxia to varying degrees of axonotmesis [45], with a wide range of prognoses [46]. The neurophysiologic consequences of neuroprosthesis design changes have been extrapolated from benchtop and animal models $[43,47,48]$ and then tracked chronically through observations of neuroprosthesis performance [1, 30]. With myriad potential etiologies and sequelae, it is crucial to grade neurophysiological changes following NCE implantation using well-established electrodiagnostic studies in chronic implant recipients. This is especially important in subjects with SCI who have limited clinical exams at baseline.

We performed the first human trial evaluating the short and long-term health of nerves implanted and stimulated with NCEs through electrodiagnostic studies preoperatively, intraoperatively, and postoperatively over 1 year. We tracked femoral motor and saphenous sensory NCS and needle EMG, NCE stimulation charge thresholds, and tetanic knee moments, before and after initiating an exercise program with stimulation. We report the electrophysiological and clinical outcomes of the first-in-man deployment of bilateral 8-contact CFINEs on the proximal femoral nerve trunks of one subject with SCI (Fig. 2).

\section{Methods}

A combination of electrodiagnostics and metrics of neuroprosthesis functional performance was employed to quantify femoral nerve health and nerve-cuff interactions at seven time-points over a 1-year period postoperatively (Fig. 3). Measures of neuroprosthesis performance included stimulation charge thresholds, tetanic knee extension moments, and measurement of weight supported through the subject's legs while standing. NCS and needle EMG systematically compared neuromuscular function to preoperative baseline levels. For the first 6 months postoperatively, percutaneous leads allowed a custom stimulator, the Universal External Control Unit, UECU, (Case Western Reserve University, CWRU, Cleveland OH) [49] to access to all 16 contacts across bilateral C-FINEs (CWRU, Cleveland OH). After

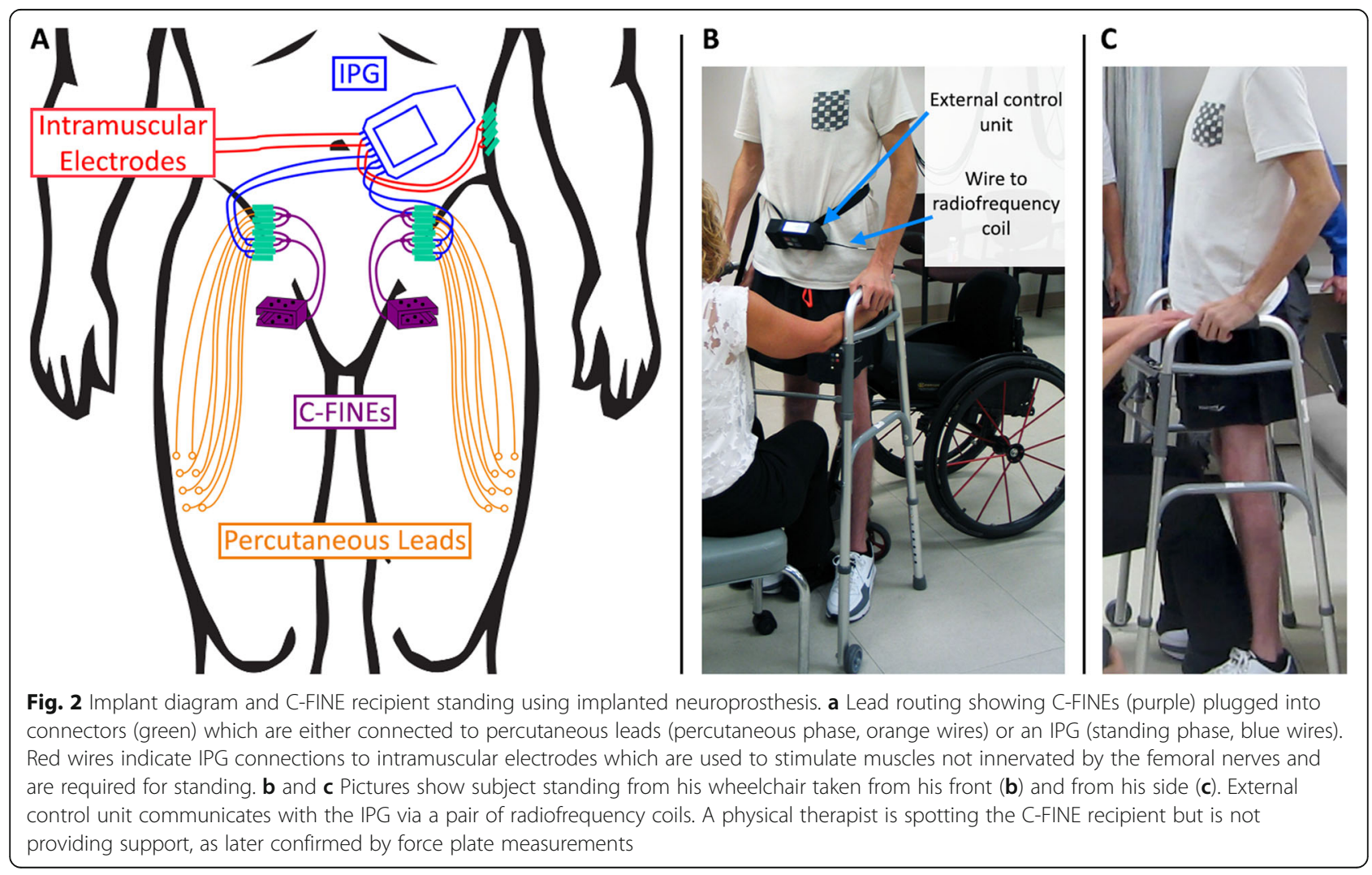




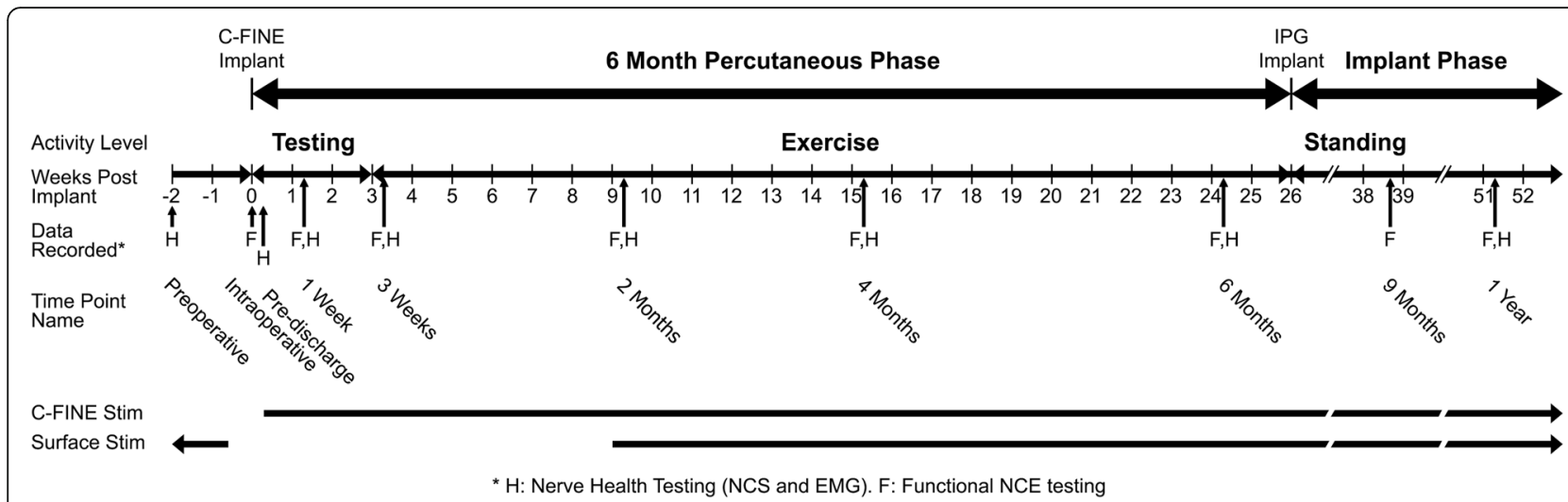

Fig. 3 Experimental timeline. "Nerve health testing," including NCS and needle EMG, was performed at 1 time-point preoperatively and 7 timepoints postoperatively. "Functional testing," including charge threshold and moment measurements, was performed intraoperatively without moment measurements and at 7 time-points postoperatively. Moment was collected at all postoperative time-points but was restricted to twitch moments only until the third week postoperatively. The percutaneous phase ended when a 16-channel IPG, full standing neuroprosthesis system was implanted. This required a reduction in the number of contacts for knee extension from 16 to 6 across both C-FINEs to allow stimulus channels to be assigned to intramuscular electrodes for hip and trunk extension

this period, percutaneous leads were removed and 3 contacts per C-FINE selective for isolated knee extension were connected to an implanted pulse generator (IPG) that delivered stimulation through these 6 contacts. The IPG in this study was the 16-channel implanted stimulator-telemeter (IST-16) developed at CWRU and the Cleveland Department of Veterans Affairs [50-52]. Electrodiagnostic studies interrogated the whole nerve either via surface stimulation delivered via a clinical Alpine Keypoint EMG Unit (Alpine Biomed ApS, Skovlunde Denmark) or via the C-FINEs when surface stimulation was impractical.

\section{C-FINE Implantation}

The C-FINE (Fig. 1a) is a NCE designed to match the naturally oblong cross section of many peripheral nerves $[38,53]$ and gently reshape them into a flatter cross section. A flattened architecture allows for isolated stimulation of functionally distinct fascicles and the placement of more stimulating contacts around a nerve [36]. The C-FINE employs graduated stiffness to reshape the nerve along the middle of the C-FINE while remaining highly flexible along the length of the nerve to accommodate nerve bending [43] (Fig. 1a, Top). The C-FINEs had 4 platinum-iridium contacts with an exposed surface area of $0.5 \mathrm{~mm}^{2}$ evenly distributed on each of the top and bottom interior surfaces of the electrode for a total of 8 contacts.

We implanted 8-contact C-FINEs bilaterally on the proximal femoral nerves of a male volunteer (age 25, 5 years post-injury) with SCI (C5 American Spinal Injury Association impairment scale C). Inclusion in this study required a subject who has little to no volitional control of muscles which would assist in standing. At preoperative baseline, the C-FINE volunteer had limited volitional control of his lower extremity muscles. Medical Research Council (MRC) manual muscle testing [54] was conducted at several visits. Preoperatively, this testing showed the following: volitional hip flexion was $3 / 5$ (strength against gravity) on the right, and was $2 / 5$ (strength parallel to gravity) on the left; and knee extension was $2 / 5$ bilaterally. These results were consistent with the inclusion criteria.

Lower density (i.e. 4-contact) NCEs do not have the resolution to separately activate distinct functional groups of fascicles on the common femoral nerve trunk proximal to branches to both knee extensors and hip flexors [55]. The anticipated selectivity of 8-contact CFINEs [37] justified implanting the devices at this location. Because of the potential of the femoral nerve at this site to move and bend beneath the inguinal ligament during hip flexion [39-42], a surgeon verified that the C-FINEs did not get compressed or pulled underneath the ligament with each hip flexed to near $90^{\circ}$. A redundant loop for strain relief (Fig. 1b) was left in the distal leads close to the C-FINEs prior to subcutaneous tunneling to proximal connector sites in the abdomen. The strain relief loop reduced the potential for transmitting tethering forces to the devices or nerves during hip movement.

Intraoperatively, an external stimulator, the UECU elicited contractions via stimulation through the C-FINE contacts. Monopolar EMG needles inserted into muscles innervated by the femoral nerve (Fig. 1d), recorded the evoked EMG intraoperatively to calculate stimulation charge thresholds and motor nerve conduction velocities (MNCVs). Following EMG recording, the leads from the C-FINEs were first passed to abdominal spring-and-pin 
connectors [56]. Helical wound percutaneous leads [57, 58] connected to each C-FINE allowed access to all 8 individual contacts. These percutaneous leads were then tunneled subcutaneously and individually to exit sites on the proximal anterolateral thighs (Fig. 2a). The subject cleaned, monitored, and re-dressed the percutaneous interfaces for the next 6 months, during which time he experienced only minor complications such as an occasional mild erythema (white arrow in Fig. 1c).

Intraoperatively and 3 weeks post-implantation, stimulation with single pulses of stimulation avoided tetanic contractions and minimized risk of NCE movement. Following this 3 -week period, we initiated exercise paradigms with tetanic stimulation. Following the 6-month percutaneous phase, the subject received a fully implanted standing neuroprosthesis (Fig. 3). Percutaneous leads were removed and 6 out of 16 C-FINE contacts for isolated knee extension bilaterally were connected to an IPG, along with intramuscular electrodes for hip and trunk extension bilaterally, including bilateral quadratus lumborum, erector spinae, gluteus maximus, and posterior portion of adductor magnus and unilateral hamstring (right) and gluteus medius (left) (the "Intramuscular Electrodes" shown in Fig. 2a).

\section{Electrodiagnostic testing}

Before implantation and throughout the 1-year follow up period, a neurologist subspecializing in electrodiagnostics and neuromuscular diseases conducted all electrodiagnostic testing. Two weeks prior to implantation, NCS and needle EMG studies evaluated baseline nerve health. Preoperative NCS of bilateral lower extremities quantified saphenous, sural, and superficial peroneal sensory nerve action potentials
(SNAPs), and peroneal, tibial, and femoral CMAPs. Examples of typical rectus femoris (RF) CMAPs and saphenous nerve SNAPs are shown in Fig. 4 along with illustration of calculation of their amplitude and area. Needle EMG was performed on 9 muscles per leg innervated by these nerves. EMG was interpreted by an experienced electromyographer according to clinical standards $[59,60]$. Spontaneous activity, such as fibrillation potentials, was scored on an ordinal scale to indicate the frequency and proportion of areas showing these discharges. Pre- and post-operative testing focused on NCS of the femoral and saphenous nerves, and needle EMG of femoral nerve innervated muscles, including vastus medialis (VM), vastus lateralis (VL), RF, and sartorius (Sart). Vastus intermedius (VI) was not included because it is not routinely included in routine clinical needle EMG testing, and we aimed to apply methods that were consistent with established clinical practices in this study for future reproducibility.

Saphenous SNAPs were elicited with surface stimulation of sensory fibers on the medial calf, between medial gastrocnemius and the tibia, $14 \mathrm{~cm}$ proximal to recording electrodes. The SNAP was recorded with bar electrodes with the active electrode midway between the tibialis anterior tendon and the medial malleolus and reference electrode positioned distally [61, 62]. For the purposes of this study where the NCEs were placed on the femoral nerves, postsurgical testing focused on the femoral motor nerve responses, and its terminal nerve branch, the saphenous sensory nerve. It was helpful to track the saphenous studies, since sensory responses are three orders of magnitude smaller than motor responses, and hence more susceptible to axonal or demyelinative nerve damage [63].

\section{Typical CMAP Response}

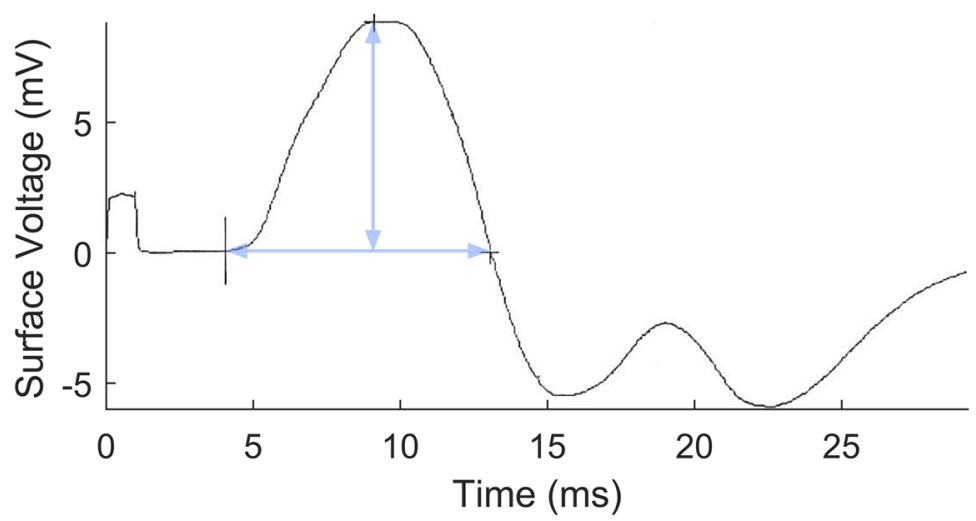

Typical SNAP Response

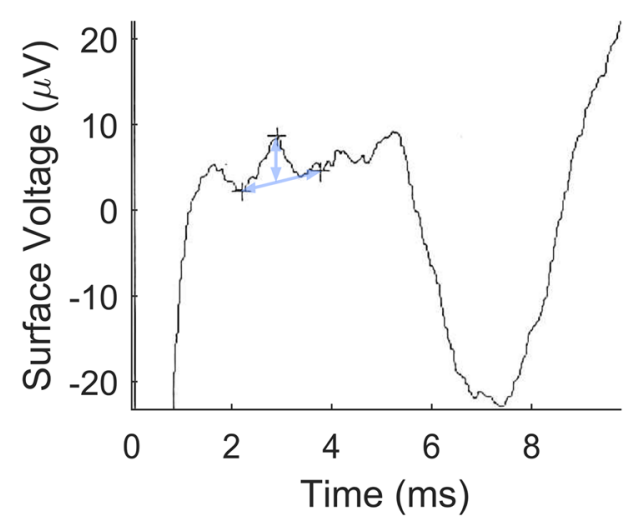

Fig. 4 Example of typical CMAP and SNAP. CMAP (left) of RF after surface stimulation of femoral nerve. Blue arrows indicate duration (horizontal) and amplitude (vertical) of the CMAP which gave an amplitude of $8.8 \mathrm{mV}$, and area of $47.8 \mathrm{mV}$ ms. SNAP of the saphenous nerve (right) was recorded after stimulation of sensory fibers. The stimulus artifact extended to roughly $-40 \mu \mathrm{V}$ on this plot but was cropped for readability. Blue arrows again measure duration and amplitude and this SNAP had an amplitude of $4.2 \mu \mathrm{V}$ 
CMAPs were elicited either with surface stimulation ("surface-elicited") of the femoral nerve at the groin using standard commercially available electrodiagnostic test equipment (Alpine Keypoint) or via stimulation through the C-FINEs ("C-FINE-elicited") via the custom stimulator (the UECU initially and then the IST-16 once implanted). Responses were always recorded at RF with surface electrodes using clinical EMG equipment (Alpine Keypoint). The surface stimulation and recording represent the clinical standard of care and are generally preferred to replicate clinical practice. However, measurements made while stimulating through the CFINEs allowed additional testing, including CMAP measurements made with the subject sitting (hip flexed to $90^{\circ}$ ) compared to supine to evaluate for potential femoral nerve compression during hip flexion. Surface stimulation of the femoral nerve with hips flexed is impractical since the groin is blocked. Additionally, surface stimulation over the surgical site was contraindicated in the perioperative period (through the 3-week time point) making stimulation via the C-FINEs necessary during this time period.

Three weeks postoperatively, custom pre-programmed stimulation paradigms $[12,64]$ were initiated to recondition the knee extensor musculature. The exercise paradigm generated contractions of quadriceps muscles to build knee extension strength with high load and low repetition exercises with progressively increasing ankle weights while sitting. To build endurance, the stimulation paradigms utilized long duration and low load exercises. These exercise programs continued throughout the 6-month percutaneous phase. After 6 months, the standing phase began with implantation of the IPG [50, 51]. The subject continued to build knee extension strength and endurance with a take-home standing rehabilitation program, which he began to use approximately 6 weeks after IPG installation (8 months after CFINE implantation).

\section{EMG evaluating Neuroprosthesis function}

Intraoperatively and at all postoperative time-points, pairs of monopolar EMG needles recorded the responses to stimulation delivered through the C-FINEs. These determined stimulation thresholds, saturations, and functional responses. During the 6-month percutaneous period, the externalized leads to the C-FIINE contacts were connected to a custom-designed current-controlled stimulator (UECU) that delivered monopolar, chargebalanced, biphasic pulses with pulse amplitude ranging from 0.1 to $2.0 \mathrm{~mA}$ and pulse widths ranging from 1 to $255 \mu$ s. A surface return electrode was placed over the left lower quadrant of the abdomen, which was chosen to best replicate the future site of the IPG. When the IPG was implanted, the titanium case was sutured to the abdominal fascia and acted as the return electrode. Pulse amplitude was limited so that charge densities per phase remained under the suggested level for electrical stimulation given by:

$$
\log (Q D)=k-\log (Q)
$$

where QD is the charge density per phase $\left(\mu \mathrm{C} / \mathrm{cm}^{2}\right)$ and $Q$ is charge per phase $(\mu C)$ [65]. Based on prior work, $\mathrm{k}<1.5$ is considered safe for continuous pulse trains up to frequency of $50 \mathrm{~Hz}$ [66-68]. We limited pulse amplitude so that $\mathrm{k}$ was less than 1.5 for all injected charges. In most cases, pulse amplitudes were $0.8 \mathrm{~mA}$ and occasionally up to $1.4 \mathrm{~mA}$. "Twitch stimulation" involved stimulating with a single pulse with at least $1 \mathrm{~s}$ between pulses. "Tetanic stimulation" delivered a train of pulses at $20 \mathrm{~Hz}$.

Prior to stimulation, a surface reference electrode (2" $\times 4$ ", Nicolet-VIASYS, Madison, WI) was placed over the greater trochanter of the contralateral leg. R.A. placed monopolar EMG needle electrodes (Nicolet 27 to 28 gauge needles, $13 \mathrm{~mm}-50 \mathrm{~mm}$ length (Natus Medical Inc., Pleasanton, CA) approximately $2 \mathrm{~cm}$ apart into knee and hip extensor muscles innervated by the femoral nerve (Fig. 1d). EMG was recorded independently and simultaneously from the three heads of the vasti (VM, VI, VL), RF, and Sart.

Stimulation delivered through each contact on the CFINEs at all measurement intervals elicited twitch EMG responses. Each pair of EMG needle electrodes was ACcoupled to a differential amplifier (B\&L Engineering, Tustin, CA) with passband $12-2975 \mathrm{~Hz}$ and gain 325 . Programmable amplifiers (1902, Cambridge Electronic Design, CED, Cambridge, UK) further low-pass filtered at $1 \mathrm{kHz}$ and amplified the signal for a total gain of 1155. An A/D DAQ board (BNC-6259, National Instruments, Webster, TX) sampled the signal at $2.5 \mathrm{kHz}$ and custom MATLAB (MathWorks, Natick, Massachusetts) code interfaced with the programmable amplifiers and the UECU. EMG responses of each muscle were rectified, integrated over the duration of the M-wave ( $3 \mathrm{~ms}$ to up to $30 \mathrm{~ms}$ after stimulation), and normalized by the maximum twitch for the muscle following supramaximal stimulation on all contacts [69] at either 0.8 or $1.4 \mathrm{~mA}$ and $255 \mu \mathrm{s}$. These EMG twitches were repeated 3 times at every stimulation parameter to provide a mean and standard deviation for each stimulation input. The distance between each muscle and the C-FINE was approximated by measuring the distance from surgical scar to EMG needles over the surface of the thigh. Dividing the distance between the C-FINE and the recording needles for each muscle by the onset latency of the CMAP for that muscle determined MNCVs. Onset latency was 
defined as the time between stimulation and M-wave onset, with a $0.5 \mathrm{~ms}$ offset to approximate neuromuscular junction delay [70, 71]. The MNCVs averaged across all of the muscles provided the conduction velocity for the femoral nerve.

Calculation of the stimulation threshold charges follows:

$$
Q_{\theta}=I x P W_{\theta}
$$

The current, I (either $0.8 \mathrm{~mA}$ or $1.4 \mathrm{~mA}$ ) applied through each contact was the minimum current able to reach supramaximal stimulation by the maximum pulse width of $255 \mu \mathrm{s}$. Thus, supramaximal contractions were elicited either with a pulse amplitude of 0.8 or $1.4 \mathrm{~mA}$ or at a pulse width of $255 \mu \mathrm{s}$. Current was adjusted on a contact-by-contact basis, but remained consistent for each contact across all time-points to eliminate a potential source of variability in charge threshold calculations $[72,73] . P W$ was defined as the pulse width at which EMG response reached $10 \%$ of its supramaximal stimulation value. Charge threshold stability based on EMG was tracked for all 16 contacts during the 6 month percutaneous phase, and then derived from the moment measurements for the 6 contacts connected to the IPG at 9 months and 1 year postoperatively.

\section{Surrogate measures of muscle strength}

Starting at 3 weeks postoperatively, and for all remaining time-points, a 6 degree-of-freedom load cell (JR3 Inc., Woodland, CA) measured isometric, tetanic knee extension moments via software written in LabVIEW (National Instruments, Austin, TX) and MATLAB with the knee fixed at $20^{\circ}$ flexion and with the distal thigh fixed to the seat of a robotic dynamometer (Biodex, Shirley, NY). The load cell was employed, rather than the dynamometer measurement head, for its superior sensitivity and noise characteristics which were particularly important for recruitment properties close to threshold which are critical to assessing selectivity. The dynamometer head was aligned with the center of rotation of the knee so the torque measured at the load cell matched that at the knee. Moment data were low passed filtered at $31.25 \mathrm{~Hz}$, sampled at $150 \mathrm{~Hz}$, normalized by the subject's body mass ( $54.5 \mathrm{~kg}$ initially) and reported in $\mathrm{Nm} / \mathrm{kg}$.

Tetanic stimulation was delivered through each contact at $20 \mathrm{~Hz}$ for approximately $3 \mathrm{~s}$ with at least $15 \mathrm{~s}$ of rest between repeated bursts to avoid fatigue, as described for previous standing neuroprosthesis studies [26]. We determined whether there was a significant linear relationship between knee moment and time-point in the study by fitting a linear regression to the yearlong mean moment data for each leg and using a t-test on the null hypothesis that slope of the fitted line is 0 , which would indicate no change as a result of stimulated exercise.

As a secondary measure of quadriceps strength and reconditioning, thigh circumference was measured at all postoperative time-points and compared to a preexercise baseline. The same individual consistently measured circumference at a site $15 \mathrm{~cm}$ proximal to the site of attachment of the quadriceps tendon to the patella. By assuming the thigh was approximately circular in cross section, a squared ratio of circumferences provided an estimated ratio of areas.

To be functionally relevant, stimulation must generate moments sufficient and stable enough to support a subject's body weight through the feet. Starting approximately 7 months postoperatively, standing with stimulation was added to the exercise and rehabilitation program. The subject positioned his feet on a set of force plates (AMTI, Watertown MA) to measure right and left ground reactions while he maintained quiet standing with his heuristically tuned take-home "standing" stimulation pattern. He used a walker that was wider than the force plates to assist with balance so that only the body weight transmitted to the ground through his feet were recorded. The vertical components of the ground reaction forces at his feet were normalized by his body mass to calculate percentage of body weight supported by the lower extremities.

\section{Results}

Preoperative needle EMG showed limited activation with otherwise normal motor unit potential morphology and recruitment patterns in the bilateral tensor fascia lata and right flexor digitorum longus muscles. No other tested muscle in the bilateral lower extremities showed volitional activity: Sart, RF, VL, VM, tibialis anterior, medial gastrocnemius, nor extensor hallucis longus. Preoperatively, no tested muscle revealed electrophysiologic evidence for active or chronic denervation. At baseline, sensation was decreased (50\% of normal) to light touch and absent to pinprick throughout the lumbosacral dermatomes, including the saphenous nerve distribution.

Preoperative NCS in the lower extremities revealed essentially normal bilateral sensory nerve (saphenous, superficial peroneal and sural) and motor nerve (femoral, peroneal and tibial) responses. The left saphenous sensory response showed borderline decreased amplitude, but was otherwise normal. Preoperative NCS and EMG were consistent with a central etiology, such as $\mathrm{SCI}$, for his clinical weakness.

\section{Motor nerve conduction studies}

C-FINE stimulation with recording at all heads of the quadriceps revealed consistent, symmetric, and normal 
MNCV above $41 \mathrm{~m} / \mathrm{s}$ (one sample t-test $p<0.05$ that the average $\mathrm{MNCV}>41$ ) throughout the 24-week percutaneous phase of the study (Fig. 5a). Although there was an apparent decrease in MNCV from intraoperative measurements compared to 1 week postoperatively, this drop was not statistically significant ( $p=0.3$ on the left and $p=0.07$ on the right). There was no statistically significant difference between the MNCVs on the right as compared to the left $(p=0.06)$. Femoral nerve latencies elicited by surface stimulation at the inguinal ligament

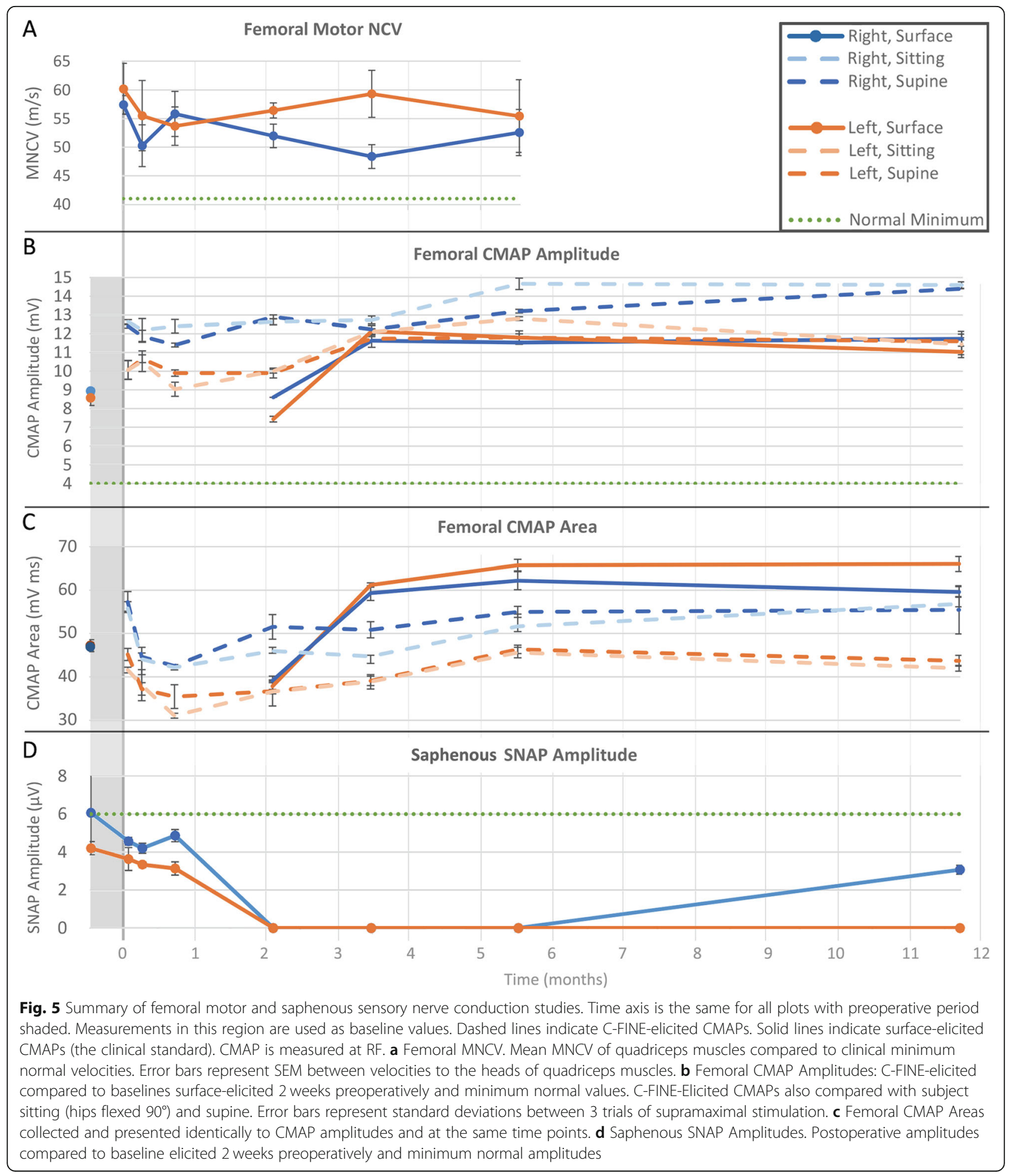


and measured at the RF were recorded preoperatively and again at 2, 4, 6, and 12 months. These were always within normal limits $(<6 \mathrm{~ms})$.

Both surface-elicited (solid lines in Fig. 5b and c) and C-FINE-elicited (dashed lines) CMAPs showed increasing amplitudes and areas over the course of this 1-year. The increase in CMAP amplitude and area occurred after the subject started his rehabilitation exercise program 3 weeks postoperatively. Surface-Elicited-CMAP amplitudes and areas were above baseline at all timepoints except one, 2 months postoperatively, when amplitudes averaged $9.6 \%$ and areas $18.2 \%$ below baseline bilaterally. This time-point correlated with an increase in the stimulation threshold (discussed below), which limited the ability for supramaximal stimulation via surface stimulation. In contrast, C-FINE-elicited CMAP amplitudes at 2 months essentially equaled $(+1.5 \%)$ baseline CMAPs. This indicates that the dip in surface-elicited CMAPs at 2 months may be due to increased subcutaneous cellularity or other difficulty achieving a full stimulated contraction percutaneously. By 6 months postoperatively, with regular exercise, surface-elicited CMAP amplitudes and areas increased by an average of 31 and 34\%, respectively. From 6 months to 1 year postoperatively, all CMAP values were stable and essentially unchanged by the standing exercises initiated around 8 months postoperatively. There was no significant decrease (paired t-test, $p=0.06$ on the right and $p=0.85$ on the left) in the C-FINE elicited CMAP amplitudes secondary to hip flexion.

\section{Sensory nerve conduction studies}

Saphenous SNAP amplitudes were normal in the right lower extremity, and borderline normal in the left lower extremity. Bilateral saphenous sensory responses were stable at 3 weeks postoperatively, but absent by 2 months (Fig. 5d). The right saphenous SNAP started to recover by the 1 year test date; however, the left saphenous response remained absent until this time-point. Subjectively, the subject did not notice any clinical change in his lower extremity sensation; however, his sensation was already compromised in the setting of his SCI. When obtained, saphenous SNAPs demonstrated velocities greater than $41 \mathrm{~m} / \mathrm{s}$, ranging from 42 to $51 \mathrm{~m} / \mathrm{s}$. Return of right saphenous SNAP by the 1 year test date suggests a regeneration rate of roughly $2-3 \mathrm{~mm} /$ day from the time of surgical manipulation which is consistent with other studies for distal peripheral nerve axonal regeneration $[74,75]$.

\section{Needle EMG}

Preoperatively, needle EMG showed normal insertional activity, without any spontaneous activity. At 1, 3, and 9 weeks postoperatively, rare fibrillation potentials were seen in the following muscles: Sart and VM on the right; and Sart, RF, and VL on the left (Table 1). As expected, more proximal muscles (Sart, RF) showed signs of active denervation initially, and as the proximal muscles improved, the distal ones showed rare fibrillation potentials. No fibrillation potentials were seen at or after 15 weeks postoperatively, indicating that nerve irritation, inflammation, or damage resolved after the intraoperative or perioperative periods.

\section{Stimulation charge thresholds}

Stimulation charge thresholds were calculated for each available C-FINE channel at all time-points (Fig. 6). Fifteen out of 16 contacts had charge threshold below 100 $\mathrm{nC}$ at every time-point and the remaining contact's charge threshold only exceeded $100 \mathrm{nC}$ for a single measurement. The mean of the charge thresholds was lowest at implantation at $9.7 \mathrm{nC} \pm 1.7$ (SEM) over all contacts. These rose postoperatively, and peaked around 2 months at $45.8 \mathrm{nC} \pm 6.9$ (SEM). At the end of the 6month percutaneous phase, thresholds across all 16 contacts averaged $27.8 \mathrm{nC} \pm 4.4$ (SEM). At 6 months the mean threshold across the 6 contacts selected to be connected to the IPG was $28.1 \mathrm{nC} \pm 9.2$ (SEM), and at 1 year it was $19.7 \mathrm{nC} \pm 6.2$ (SEM), revealing that thresholds continued to decrease as expected. Most of this drop occurred by 9 months after which values appeared to plateau. By 1 year, the thresholds appeared to be stable and were not expected to decline further [2]. These charge thresholds and the time course of their changes are consistent with previous NCE studies [2, 26].

Table 1 Summary of locations and time-points of active denervation. Active denervation never exceeded rare fibrillation potentials at any time-point or location. First column indicates distance from C-FINEs to where EMG needle typically inserted in muscle. Yellow (right leg) and blue (left leg) boxes indicate rare fibrillation potentials at a specific time-point. Sart, sartorius; RF, rectus femoris; $\mathrm{VL}$, vastus lateralis; $\mathrm{VM}$, vastus medialis

\begin{tabular}{l|cccc} 
Distance $(\mathrm{cm})$ & 5 & 15 & 40 & 42 \\
Muscle & Sart & $\mathrm{RF}$ & $\mathrm{VL}$ & $\mathrm{VM}$ \\
\hline Preoperative & & & & \\
\hline Pre-discharge & & & \\
\hline 1 Week & & & \\
\hline 3 Week & & & \\
\hline 2 Month & & & \\
\hline 4 Month & & & \\
\hline 6 Month & & & \\
\hline 1 Year & & &
\end{tabular}



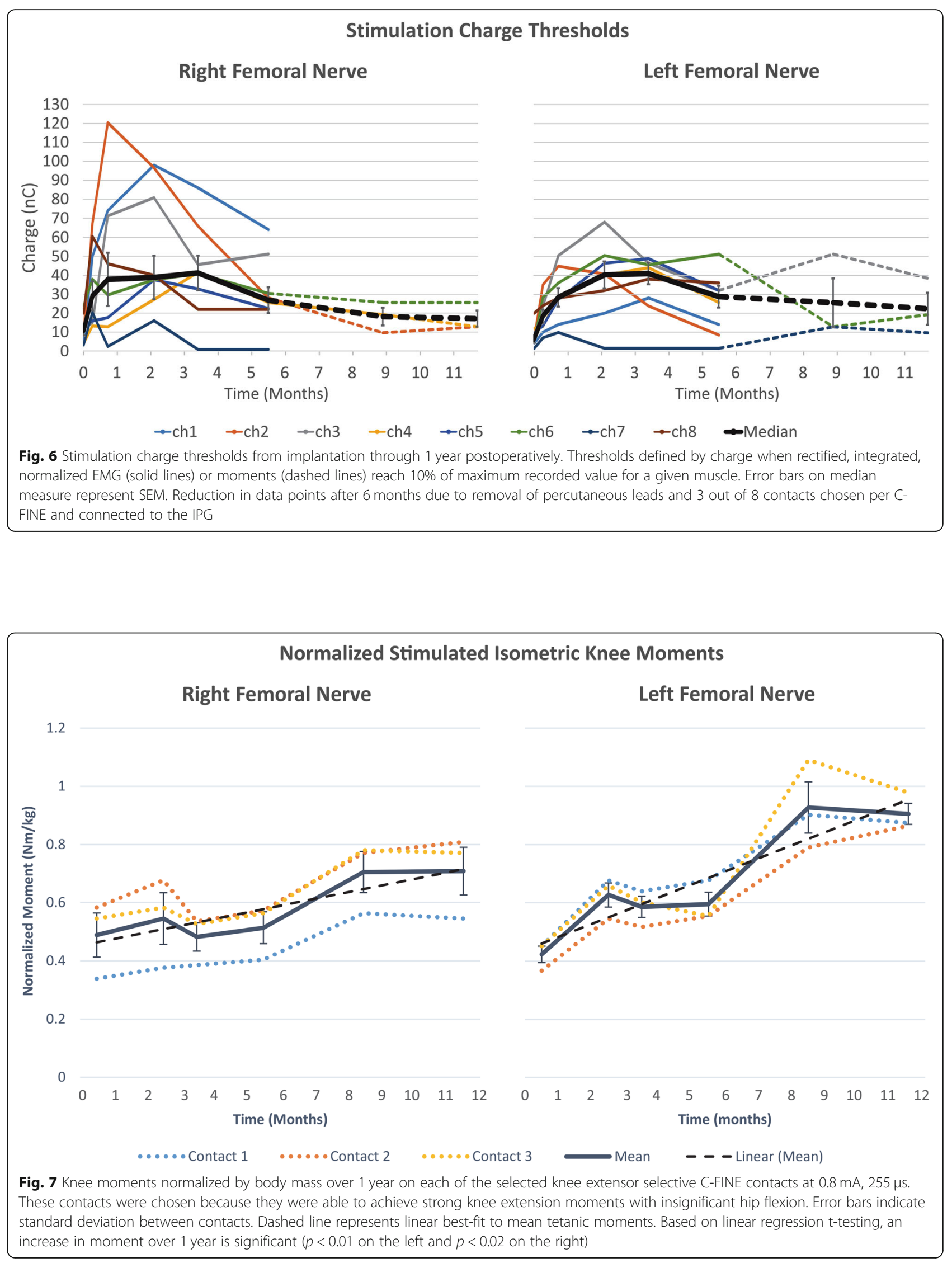


\section{Surrogate markers for muscle strength}

From the initiation of tetanic stimulation through 1 year of neuroprosthesis use for exercise and standing, maximum single-contact tetanic knee extension moment for the 6 contacts connected to the IPG increased by an average of $79 \% \pm 16$ (SEM) (Fig. 7). Linear regression ttests demonstrated a significant increase in moment during this study on both the left $(p<0.01)$ and right $(p<$ $0.02)$ legs. The initial average moment of $0.42 \mathrm{Nm} / \mathrm{kg}$ per contact on the left increased by $110 \%$ to produce an average moment of $0.89 \mathrm{Nm} / \mathrm{kg}$ per contact. The initial average moment of $0.49 \mathrm{Nm} / \mathrm{kg}$ per contact on the right increased by $44 \%$ to produce an average moment of $0.70 \mathrm{Nm} / \mathrm{kg}$ per contact. Despite these increases in stimulated knee moments, repeated manual muscle testing did not indicate any consistent nor functional significant change in volitional knee moment.

Over the first 5 months of stimulated exercise, thigh circumference increased by 11 and $12 \%$ (from 31.0 to $34.4 \mathrm{~cm}$ and from 30.5 to $34.3 \mathrm{~cm}$ ) on the right and left sides, respectively. With the addition of stimulated standing exercise in the second phase of this trial, thigh circumference increased an additional 6\% (to $36.5 \mathrm{~cm}$ ) on the right and $8 \%$ (to $37.0 \mathrm{~cm}$ ) on the left by 1 year. This resulted in total circumference gains of 18 and $21 \%$ on the right and left thighs, respectively. Thigh crosssectional areas derived from these circumference measurements, increased by $39 \%$ on the right and $47 \%$ on the left, suggesting increases in force generating capacity with reconditioning exercise and standing [76, 77].

Approximately 7 months postoperatively, the subject began standing with his take-home "standing" patterns of stimulation. Force plate data from roughly $5 \mathrm{~min}$ of quiet standing showed that $93.1 \pm 2.1 \%$ of his body weight was supported by his legs while standing (Fig. 8).

\section{Discussion}

This study reports the neurophysiological results secondary to implantation of C-FINEs on bilateral femoral nerves as part of a standing neuroprosthesis in a subject with cervical SCI. While a larger number of NCEs across more subjects and different nerve sites will help bolster these results in the future, there are several important implications from this study. Our findings represent baseline electrodiagnostic measures and changes that can be reasonably expected over 1 year of implantation and chronic use of C-FINEs on peripheral nerves.

There are multiple possible etiologies for the mild electrodiagnostic changes seen on EMG testing. Nerve manipulation during dissection and NCE placement can cause neurapraxia or mild axonotmesis. C-FINE movement along the nerve in the perioperative period, prior to stabilization with encapsulation tissue, could also cause nerve irritation. Fibrillation potentials seen with needle EMG started approximately 1 week after surgery and cleared between 9 to 15 weeks postoperatively. This time course is consistent with neurapraxia or mild axonotmesis occurring during NCE implantation, revealing that there was not on-going denervation or irritation.

The surface-elicited CMAP amplitudes and areas decreased by roughly $20 \%$, at 2 months (Fig. $5 \mathrm{~b}$ and c solid lines). However, C-FINE-elicited CMAPs (dashed lines) were similar to baseline at the 1-2-month timeframe. This discrepancy is associated with a significant increase

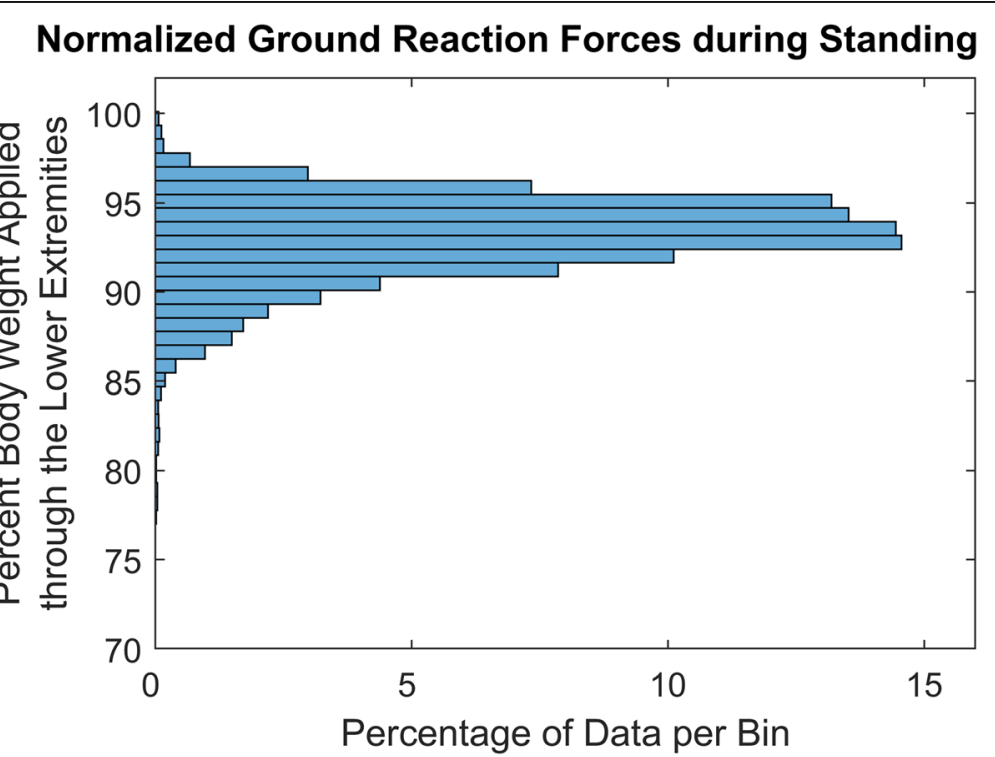

Fig. 8 Histogram of summed and normalized vertical component of ground reaction forces measured during quiet standing with take-home "standing" pattern, indicating percentage of body weight supported through legs 
in the stimulation charge threshold at this point. The elevated threshold may have limited the ability to reach a supramaximal response, especially through surface stimulation. Increases in stimulation charge thresholds in the first several months postoperatively is often attributed to inflammation between electrode and nerve and is well established [2, 26, 30]. A similar increase in charge thresholds was observed for stimulation through the C-FINEs in this study, which rose almost five-fold over the first 2 months postoperatively. However, over the last 10 months of this study, thresholds consistently declined and stabilized as expected.

NCS also revealed saphenous SNAP loss and partial recovery between 6 months to 1 year. Combined with the presence of temporary mild fibrillation potentials, these findings are consistent with mild axonal loss and regeneration [45, 78]. The rate of recovery for the right saphenous SNAP is consistent with established axonal regeneration rates $[45,46]$ and support temporary, perioperative irritation. Postsurgical neurapraxia tends to have a positive prognosis [79] and these results show a positive functional outcome in this subject. Moreover, the subject reported no appreciable changes in his 50\% preserved sensation over the saphenous dermatome at any time. All other studies indicated that the C-FINEs had a positive impact on the rehabilitation potential for the muscles innervated by the femoral nerves, and improved functional status. We recommend that electrodiagnostic studies be used to track neurophysiological changes due to an implanted NCE, since this data will allow for clinical determinations about NCE viability and nerve health.

Despite mild changes in neurophysiology, the standing neuroprosthesis deployed in this study was clinically successful. After 3 months of training, this subject was able to stand in excess of 30 min (Figs. 2 and 8), after being wheelchair dependent for the previous 5 years. These standing times may be attributable to the performance of the C-FINEs, although it should be noted that standing times produced by neuroprostheses are extremely variable and dependent on a multitude of factors $[1,80]$. Each of the three individual contacts within each CFINE generated four times the $0.135 \mathrm{Nm} / \mathrm{kg}$ of knee extension [81-83] required for quiet standing, and each CFINE generated twice the $0.4 \mathrm{Nm} / \mathrm{kg}[83,84]$ required for the sit-to-stand transition. In fact, biomechanical measurements indicated that all of his body weight, excluding his arms $[85,86]$, was supported by his legs while standing (Fig. 8). Although these knee moments and standing times may be influenced by the subject's relatively low body mass, adherence to the exercise and rehabilitation protocol, or other factors, the performance of the nerve-based electrodes made a considerable contribution to the functional outcome. A deeper discussion of the functional efficacy of the C-FINEs and their selectivity over time can be found in another study [87] where we detailed the ability of the C-FINEs to separate knee extension from hip flexion, independently activate separate populations of knee extensor motor units, and document recruitment patterns and selectivity changes over time-intraoperatively, perioperatively, and chronically. This increased selectivity can be used to recruit functionally disparate groups of muscles, as well as to use synergistic muscles to delay fatigue [88] or increase the dynamic range of force generation.

After 1 year of various quadriceps focused exercises, notable increases or improvements were noted in muscle bulk, strength generated with stimulation, and electrodiagnostic measures. Bilaterally CMAPs increased an average of $31 \%$, and isometric moments increased an average of $79 \%$. Amplitudes and areas of femoral CMAPs increased during the initial 6 months of exercise with stimulation through the NCE. However, there was no appreciable increase from 6 months to 1 year, despite significant increases in elicited knee extension moment and thigh circumference indicating muscle hypertrophy. Notably, CMAP amplitudes, areas, and duration remained unchanged with hip flexion, indicating that the C-FINE was flexible enough to accommodate nerve bending in proximity to the inguinal ligament.

This study utilized clinically-standard semiquantitative interpretation of needle EMG activity, in particular with regard to classifying the amount of spontaneous activity. Following these standards for EMG interpretation allow an experienced electromyographer to quickly record from several muscles, lowering the barrier for this type of testing. However, they require the time of an experienced electromyographer and may not capture the full variability in responses across the sampled muscles. For instance, the standard deviation calculated on twitch CMAPs (Fig. 5b and c) were calculated from three supramaximal twitches during a single testing session. This does not capture the possible variability expected from day to day, at different extremity temperatures [89], or across variations in recording electrode placement. Additionally, three samples affords only two degrees of freedom which increases the range of a confidence interval in a t-distribution roughly 2-4 fold compared to higher degrees of freedom [90]. Future studies may benefit by exploring other quantitative EMG methods $[59,78]$ or expanding the number of stimuli performed at each parameter set [91].

Limitations of this study included session-to-session variability in isometric moment measurements, which were attributed to several factors. First, there was inconsistency with day-to-day differences in muscle fatigue. This unpredictability is exaggerated in individuals with $\mathrm{SCI}$, especially during stimulation induced contractions 
of the paralyzed muscles [92]. Additionally, there may be methodological or technical sources of variability, such as the uncertainty repeated positioning of the knee during dynamometer measurements of knee moment. Isometric knee extension moments were measured at $20^{\circ}$ of knee flexion to reduce the risk of injury during tetanic contractions with the knee flexed due to the lengthtension properties and moment arm of the quadriceps. At this angle isometric knee extension moments are highly sensitive to changes in knee angle. At $20^{\circ}$ of knee flexion, moment is about $38 \%$ of maximum (occurring around $80^{\circ}$ knee flexion). If the knee is flexed to $30^{\circ}$, moment rises to roughly $51 \%$ of maximum, and if the knee is extended to $10^{\circ}$, the moment falls to $29 \%$ of maximum [93]. Thus, changes in $10^{\circ}$ from the target knee angle of $20^{\circ}$ of flexion can result in a rise of $34 \%$ or drop of $23 \%$. Despite the multiple sources of variability, increase in knee moment during the study were statistically significant $(p<0.01)$ and averaged $79 \%$ across both legs. These gains are large enough to be clinically significant as well. Although not statistically significant, the moment gains were much larger in the left leg $(110 \%)$ than the right (44\%). At baseline, there was more atrophy and weakness in his left lower extremity, possibly due to asymmetric disuse and deconditioning resulting in him favoring his right leg. The C-FINE stimulation and rehabilitation paradigms may have compensated for the asymmetry and allowed him to use both his legs equally, so that by the end of the study weight bearing on his legs during standing with the neuroprosthesis was more symmetric. Another limitation is the potential variability in calculating MNCV as we have here. The ideal measurement would be along a known and repeatable portion of the nerve with stimulation at the same two locations. Because we did not have access to the nerve itself after electrode implantation, we had to approximate distance from C-FINE to EMG needles. Additionally, we had to use data from the literature to approximate the delay at the neuromuscular junction. These factors may have made our MNCV measurements less accurate than they otherwise could be.

Another limitation is that all 16 contacts of the CFINEs were only accessible during the 6-month percutaneous phase, after which 6 out of the 16 contacts were chosen for connection to an IPG for future use during exercise and standing. This meant that knee extension moment could not be tracked with stimulation through all 16 contacts after 6 months. This is largely mitigated because the 6 contacts were specifically selected based on their ability to strongly activate and isolate distinct populations of knee extensors. A similar limitation is that stimulation charge thresholds were tracked through only these 6 contacts after the percutaneous phase ended, and charge thresholds at 9 months and 1 year were derived from moment data rather than EMG measurements. However, it is unlikely that this change in methodology would impact the outcome as the link between CMAP areas and moment generation are well established [94].

C-FINE-Elicited CMAP amplitudes are larger than surface-elicited CMAP amplitudes. However, the opposite relation holds for CMAP areas. This is likely due to limitations in the stimulator used in this study which requires $1 \mathrm{~ms}$ between deliveries of stimulation on different contacts. Over 8 contacts, a $7 \mathrm{~ms}$ delay develops from stimulation on the first through eighth contacts. This can cause excitation of some populations of motor units while others are in their refractory period, resulting in reduced CMAP areas. When charge required for supramaximal stimulation increases these effects are exaggerated because stimulation of all motor units relies more heavily on charge delivered by multiple contacts which are temporally out-of-phase.

It is not surprising that EMG measured electrodiagnostic changes in the setting of surgery with nerve manipulation and NCE implantation. However, it is remarkable that the EMG findings of fibrillation potentials and SNAP alterations are relatively minor and transient, with minimal clinical relevance. It is also crucial to balance these findings with the marked clinical benefits and restored function obtained with these neuroprostheses. For instance, this standing neuroprosthesis helped this subject achieve long standing times shortly after full system implantation. This research lays the groundwork for determining which electrodiagnostic findings may be expected, and the time-course over which they may resolve. Observing active denervation on EMG more profound or persistent may suggest that NCEs are causing ongoing irritation or nerve compromise. Based on the severity of the changes, the clinical course and medical management of implant recipients can be adjusted, and NCEs removed or replaced accordingly.

\section{Conclusions}

This is the first human trial reporting the year-long clinical electrophysiological changes and rehabilitative improvements in a subject following the application of and stimulation through NCEs. The robust and increasing femoral motor responses, in conjunction with the temporary EMG signs of neurapraxia and irritation perioperatively, establish that the C-FINEs were safely implanted on the proximal femoral nerve trunks with signs of only minor perioperative irritation. Hip flexion and the proximity of the C-FINEs to the inguinal ligaments did not result in entrapment mononeuropathy. These outcomes accompany deployment of a neuroprosthesis enabling standing and exercise 6 years after SCI. For this particular NCE design, these results suggest 
that C-FINEs may be implanted near joints and other technically demanding areas with minimal and temporary effects on nerve health, although further study would be required for other specific anatomies. There are numerous broader implications for novel NCE design and deployment. Prior to this study it was unclear if subtle changes in electrodiagnostics would require surgical modification or removal of an NCE. These results present the electrodiagnostic findings and time course for their resolution which may be expected in a fully functioning neuroprosthesis. This suggests some of the electrodiagnostic changes which could be considered essentially subclinical compared to those requiring intervention. Moreover, this testing protocol may be employed in the initial deployment of other novel NCE designs to reassure that they are safe and these protocols are potentially applicable to other peripheral nerves anatomies.

\section{Abbreviations \\ C-FINE: Composite flat interface nerve electrode; CMAP: Compound muscle action potential; CWRU: Case Western Reserve University; \\ EMG: Electromyography; IPG: Implanted pulse generator; IST-16: 16-channel implanted stimulator-telemeter; MNCV: Motor nerve conduction velocity; NCE: Nerve cuff electrode; NCS: Nerve conduction studies; RF: Rectus femoris; Sart: Sartorius; SCl: Spinal cord injury; SNAP: Sensory nerve action potential; SEM: Standard error of the mean; VI: Vastus intermedius; VL: Vastus lateralis; VM: Vastus medialis}

\section{Acknowledgements}

The authors are grateful to the NCE recipients and their families, as well as The Advanced Platform Technology Center. They are grateful to Ardiem Medical (Indiana, PA) for fabricating the UECU and C-FINE. They are also grateful to Mr. Kevin Foglyano and Mr. Michael Miller for help preparing for and during experiments, Ms. Lisa Lombardo for her rehabilitation insights, and to Dr. Robert Daroff for his guidance and support.

\section{Authors' contributions}

MJF participated in designing the methods, performing experiments, and drafting the manuscript. GCJP was the participating surgeon. DJT participated in designing the methods and drafting the manuscript. RJT participated in designing the methods, supervising experiments, and drafting the manuscript. RA participated in designing the methods, performing and supervising experiments, and drafting the manuscript. The authors read and approved the final manuscript.

\section{Funding}

This research was funded by R01-EB001889 from the National Institute of Biomedical Imaging and Bioengineering of the $\mathrm{NIH}$ and by 101-RX001039 from the US Department of Veterans Affairs. This research was supported by NIH training grants T32- EB004314, T32- GM007250, and TL1- TR000441 and with resources provided by the Advanced Platform Technology (APT) Center of Excellence of the Louis Stokes Cleveland VA Medical Center, which is supported by NIH grant 150-RX001871.

\section{Availability of data and materials}

The study protocol, informed consent form, and individual participant data that underlie results reported in this article, after de-identification, are available from the corresponding author on reasonable request for 3 years following publication.

\section{Ethics approval and consent to participate}

All procedures took place at the Cleveland VA Medical Center in Cleveland, $\mathrm{OH}$ and were approved by the local institutional review board under investigational device exemption IDE\#G040214 from US FDA for chronic human implantation of both the C-FINE and IPG.

\section{Consent for publication}

The subject consented prior to participation to all study related procedures.

\section{Competing interests}

The authors declare that they have no competing interest.

\section{Author details}

'Department of Biomedical Engineering, Case Western Reserve University, Cleveland, OH, USA. ${ }^{2}$ Advanced Platform Technology (APT) Center, Cleveland, $\mathrm{OH}$, USA. ${ }^{3}$ Department of Surgery, Case Western Reserve University, Cleveland, OH, USA. ${ }^{4}$ Louis Stokes Cleveland VA Medical Center, Cleveland, $\mathrm{OH}$, USA. ${ }^{5}$ Department of Neurology, Case Western Reserve University, Cleveland, OH, USA.

Received: 25 September 2019 Accepted: 6 July 2020

Published online: 14 July 2020

\section{References}

1. Fisher LE, Miller ME, Bailey SN, Davis JA, Anderson JS, Rhode L, et al. Standing After Spinal Cord Injury With Four-Contact Nerve-Cuff Electrodes for Quadriceps Stimulation. IEEE Trans Neural Syst Rehabil Eng. 2008;16:4738 [cited 2012 Sep 25]. Available from: http://www.ncbi.nlm.nih.gov/ pubmed/18990650.

2. Polasek KH, Hoyen HA, Keith MW, Kirsch RF, Tyler DJ. Stimulation stability and selectivity of chronically implanted multicontact nerve cuff electrodes in the human upper extremity. IEEE Trans Neural Syst Rehabil Eng. 2009:17: 428-37 [cited 2012 Sep 25]. Available from: http://www.ncbi.nlm.nih.gov/ pubmed/19775987.

3. Guiraud D, Azevedo Coste C, Benoussaad M, Fattal C. Implanted functional electrical stimulation: case report of a paraplegic patient with complete SCI after 9 years. J Neuroeng Rehabil. 2014;11:15 [cited 2019 Nov 5]. Available from: http://jneuroengrehab.biomedcentral.com/articles/10.1186/17430003-11-15.

4. Tan DW, Schiefer MA, Keith MW, Anderson JR, Tyler J, Tyler DJ. A neural interface provides long-term stable natural touch perception. Sci Transl Med. 2014;6:257ra138 [cited 2016 Nov 8]. Available from: http://www.ncbi. nlm.nih.gov/pubmed/25298320.

5. Graczyk EL, Schiefer MA, Saal HP, Delhaye BP, Bensmaia SJ, Tyler DJ. The neural basis of perceived intensity in natural and artificial touch. Sci Transl Med. 2016;8:362ra142

6. Ortiz-Catalan M, Hakansson B, Branemark R. An osseointegrated humanmachine gateway for long-term sensory feedback and motor control of artificial limbs. Sci Transl Med. 2014;6:257re6 Available from: http://stm. sciencemag.org/cgi/doi/10.1126/scitransImed.3008933.

7. Ortiz-Catalan M, Håkansson B, Brånemark R. Real-time and simultaneous control of artificial limbs based on pattern recognition algorithms. IEEE Trans Neural Syst Rehabil Eng. 2014;22:756-64.

8. Peng CW, Chen SC, Lai CH, Chen CJ, Chen CC, Mizrahi J, et al. Review: Clinical benefits of functional electrical stimulation cycling exercise for subjects with central neurological impairments [Internet]. J Med Biol Eng. 2011:1-11 [cited 2012 Sep 25]. Available from: http://libir.tmu.edu.tw/ handle/987654321/43832.

9. Jaeger RJ, Yarkony GM, Smith RM. Standing the spinal cord injured patient by electrical stimulation: refinement of a protocol for clinical use. IEEE Trans Biomed Eng. 1989;36:720-8 [cited 2016 Nov 7]. Available from: http:// ieeexplore.ieee.org/document/32104/.

10. Braz GP, Russold M, Davis GM. Functional Electrical Stimulation Control of Standing and Stepping After Spinal Cord Injury: A Review of Technical Characteristics. Neuromodulation Technol Neural Interface. 2009;12:180-90 [cited 2016 Nov 7]. Available from: http://doi.wiley.com/10.1111/j.1525-14 03.2009.00213x

11. Hardin E, Kobetic R, Murray L, Corado-Ahmed M, Pinault G, Sakai J, et al. Walking after incomplete spinal cord injury using an implanted FES system: a case report. J Rehabil Res Dev. 2007:44:333-46.

12. Triolo RJ, Bieri C, Uhlir JP, Kobetic R, Scheiner A, Marsolais EB. Implanted functional neuromuscular Stimulation Systems for Individuals With Cervical Spinal Cord Injuries: clinical case reports. Arch Phys Med Rehabil. 1996;77: 1119-28.

13. Angeli CA, Boakye M, Morton RA, Vogt J, Benton K, Chen Y, et al. Recovery of over-ground walking after chronic motor complete spinal cord injury. N Engl J Med. 2018;379:1244-50. 
14. Arpin DJ, Ugiliweneza B, Forrest G, Harkema SJ, Rejc E. Optimizing neuromuscular electrical stimulation pulse width and amplitude to promote central activation in individuals with severe spinal cord injury. Front Physiol. 2019:10:1-9.

15. Gerasimenko Y, Gorodnichev R, Moshonkina T, Sayenko D, Gad P, Reggie EV. Transcutaneous electrical spinal-cord stimulation in humans. Ann Phys Rehabil Med. 2015;58:225-31 Elsevier Masson SAS. Available from: https:// linkinghub.elsevier.com/retrieve/pii/S1877065715000779.

16. Wagner FB, Mignardot JB, Le Goff-Mignardot CG, Demesmaeker R, Komi S, Capogrosso $\mathrm{M}$, et al. Targeted neurotechnology restores walking in humans with spinal cord injury. Nature. 2018;563:65-93 Springer US. Available from: https://doi.org/10.1038/s41586-018-0649-2.

17. Formento E, Minassian K, Wagner F, Mignardot JB, Le Goff-Mignardot CG, Rowald A, et al. Electrical spinal cord stimulation must preserve proprioception to enable locomotion in humans with spinal cord injury. Nat Neurosci. 2018;21:1728-41 Springer US. Available from: https://doi.org/10. 1038/s41593-018-0262-6

18. Donaldson N, Rushton D, Tromans T. Neuroprostheses for leg function after spinal-cord injury. Lancet. 1997;350:711 Available from: https://linkinghub. elsevier.com/retrieve/pii/S0140673697240365.

19. Perkins TA, Donaldson NN, Hatcher NAC, Swain ID, Wood DE. Control of leg-powered paraplegic cycling using stimulation of the lumbo-sacral anterior spinal nerve roots. IEEE Trans Neural Syst Rehabil Eng. 2002;10:15864 Available from: http://ieeexplore.ieee.org/ielx5/7333/24582/01114835. pdf?tp=\&arnumber=1114835\&isnumber $=24582$.

20. Possover M, Schurch B, Henle K. New strategies of pelvic nerves stimulation for recovery of pelvic visceral functions and locomotion in paraplegics. Neurourol Urodyn. 2010;29:1433-8 Available from: http://doi.wiley.com/10.1 002/nau.20897.

21. Peh WYX, Mogan R, Thow XY, Chua SM, Rusly A, Thakor NV, et al. Novel neurostimulation of autonomic pelvic nerves overcomes bladder-sphincter dyssynergia. Front Neurosci. 2018;12:1-18.

22. Possover M, Chiantera V, Baekelandt J. Anatomy of the sacral roots and the pelvic splanchnic nerves in women using the LANN technique. Surg Laparosc Endosc Percutaneous Tech. 2007;17:508-10.

23. Kobetic R, Triolo RJ, Marsolais EB. Muscle selection and walking performance of multichannel FES systems for ambulation in paraplegia. IEEE Trans Rehabil Eng. 1997;5:23-9 [cited 2017 Sep 16]. Available from: http://www. ncbi.nlm.nih.gov/pubmed/9086382.

24. Uhlir JP, Triolo RJ, Davis JAJ, Bieri C. Performance of epimysial stimulating electrodes in the lower extremities of individuals with spinal cord injury. IEEE Trans Neural Syst Rehabil Eng Publ IEEE Eng Med Biol Soc. 2004;12: 279-87 [cited 2012 Sep 25]. Available from: http://www.ncbi.nlm.nih.gov/ pubmed/15218941.

25. Triolo RJ, Liu MQ, Kobetic R, Uhlir JP. Selectivity of intramuscular stimulating electrodes in the lower limbs. J Rehabil Res Dev. 2001;38:533-44 [cited 2017 Jan 19]. Available from: http://www.ncbi.nlm.nih.gov/pubmed/11732831.

26. Fisher LE, Tyler DJ, Anderson JS, Triolo RJ. Chronic stability and selectivity of four-contact spiral nerve-cuff electrodes in stimulating the human femoral nerve. J Neural Eng. 2009;6:046010 [cited 2012 Sep 25]. Available from: http://www.ncbi.nlm.nih.gov/pubmed/19602729.

27. Raspopovic S, Capogrosso M, Petrini FM, Bonizzato M, Rigosa J, Di Pino G, et al. Restoring Natural Sensory Feedback in Real-Time Bidirectional Hand Prostheses. Sci Transl Med. 2014;6:222ra19 Available from: http://stm. sciencemag.org/cgi/doi/10.1126/scitranslmed.3006820.

28. Badia J, Boretius T, Andreu D, Azevedo-Coste C, Stieglitz T, Navarro X. Comparative analysis of transverse intrafascicular multichannel, longitudinal intrafascicular and multipolar cuff electrodes for the selective stimulation of nerve fascicles. J Neural Eng. 2011;8:036023 Available from: http://stacks.iop.org/1 741-2552/8/i=3/a=036023?key=crossref.076b77d72990c9c0654a813f806fc4ba.

29. Stieglitz T, Boretius T, Čvančara P, Guiraud D, Guiho T, Lopez-Alvarez VM, et al. On Biocompatibility and Stability of Transversal Intrafascicular Multichannel Electrodes-TIME. Converging Clin Eng Res Neurorehabil II. 2017:731-5 Springer, Cham. [cited 2017 Sep 15]. Available from: http://link. springer.com/10.1007/978-3-319-46669-9.

30. Tan DW, Schiefer MA, Keith MW, Anderson JR, Tyler DJ. Stability and selectivity of a chronic, multi-contact cuff electrode for sensory stimulation in human amputees. J Neural Eng. 2015;12:26002 IOP Publishing. Available from: http://stacks.iop.org/1741-2552/12/i=2/a=026002.

31. Christie BP, Freeberg M, Memberg WD, Pinault GJC, Hoyen HA, Tyler DJ, et al. Long-term stability of stimulating spiral nerve cuff electrodes on human peripheral nerves. J Neuroeng Rehabil. 2017;14 Available from: http://rdcu.be/t713.

32. Martin KD, Polanski WH, Schulz A-K, Jöbges M, Ziemssen T, Schackert G, et al. ActiGait implantable drop foot stimulator in multiple sclerosis: a new indication. J Neurosurg. 2017;126:1685-90 Available from: https://thejns.org/ view/journals/j-neurosurg/126/5/article-p1685.xml.

33. Guiraud D, Stieglitz T, Koch KP, Divoux JL, Rabischong P. An implantable neuroprosthesis for standing and walking in paraplegia: 5-year patient follow-up. J Neural Eng. 2006;3:268-75.

34. Burridge J, Haugland M, Larsen B, Pickering RM, Svaneborg N, Iversen HK, et al. Phase II trial to evaluate the ActiGait implanted drop-foot stimulator in established hemiplegia. J Rehabil Med. 2007;39:212-8.

35. Davis R, Houdayer T, Andrews B, Emmons S, Patrick J. Paraplegia: Prolonged Closed-Loop Standing with Implanted Nucleus FES-22 Stimulator and Andrews' Foot-Ankle Orthosis. Stereotact Funct Neurosurg. 1997;69:281-7 Available from: https://www.karger.com/Article/FullText/99889.

36. Tyler DJ, Durand DM. Functionally selective peripheral nerve stimulation with a flat interface nerve electrode. IEEE Trans Neural Syst Rehabil Eng. 2002;10:294-303.

37. Schiefer MA, Polasek KH, Triolo RJ, Pinault GCJ, Tyler DJ. Selective stimulation of the human femoral nerve with a flat interface nerve electrode. J Neural Eng. 2010;7:26006 [cited 2012 Jun 15]. Available from: http://www.ncbi.n/m.nih.gov/pubmed/20208125.

38. Gustafson KJ, Pinault GCJ, Neville JJ, Syed I, Davis JA Jr, Jean-Claude J, et al. Fascicular anatomy of human femoral nerve: Implications for neural prostheses using nerve cuff electrodes. J Rehabil Res Dev. 2009;46:973-84 [cited 2013 Jun 26]. Available from: http://www.ncbi.n/m.nih.gov/pubmed/2 0104420.

39. Naroji S, Belin LJ, Maltenfort MG, Vaccaro AR, Schwartz D, Harrop JS, et al. Vulnerability of the femoral nerve during complex anterior and posterior spinal surgery. J Spinal Cord Med. 2009;32:432-5 Available from: http:// www.pubmedcentral.nih.gov/articlerender.fcgi?artid=2830684\&tool= pmcentrez\&rendertype=abstract.

40. Moore AE, Stringer MD. latrogenic femoral nerve injury: A systematic review. Surg Radiol Anat. 2011;33:649-58.

41. Bohrer JC, Walters MD, Park A, Polston D, Barber MD, et al. Am J Obstet Gynecol. 2009;201:e1-7 Elsevier Inc. Available from: https://doi.org/10.1016/j. ajog.2009.07.023.

42. Hopper $\mathrm{CL}$, Baker JB. Bilateral femoral neuropathy complicating vaginal hysterectomy. Analysis of contributing factors in 3 patients. Obstet Gynecol. 1968;32:543-7 [cited 2016 Apr 12]. Available from: http://www.ncbi.nlm.nih. gov/pubmed/5742466.

43. Freeberg MJ, Stone MA, Triolo RJ, Tyler DJ. The design of and chronic tissue response to a composite nerve electrode with patterned stiffness. J Neural Eng. 2017;14 IOP Publishing. [cited 2017 Mar 13]. Available from: http:// iopscience.iop.org/article/10.1088/1741-2552/aa6632.

44. Rydevik B, Lundborg G. Permeability of intraneural microvessels and perineurium following acute, graded experimental nerve compression. Scand J Plast Reconstr Surg. 1977:11:179-87 [cited 2017 Jul 30]. Available from: http://www.ncbi.nlm.nih.gov/pubmed/609900.

45. Quan D, Bird SJ. Nerve conduction studies and electromyography in the evaluation of peripheral nerve injuries. Univ Pennsylvania Orthop J. 1999;12: $45-51$.

46. Robinson LR. Traumatic Injury to peripheral nerves. Muscle Nerve. 2000;23: 863-73.

47. Naples GG, Mortimer JT, Scheiner A, Sweeney JD. A spiral nerve cuff electrode for peripheral nerve stimulation. IEEE Trans Biomed Eng. 1988;35: 905-16 [cited 2016 Apr 11]. Available from: http://www.ncbi.nlm.nih.gov/ pubmed/3198136.

48. Tyler DJ, Durand DM. Chronic Response of the Rat Sciatic Nerve to the Flat Interface Nerve Electrode. Ann Biomed Eng. 2003;31:633-42 [cited 2012 Apr 28]. Available from: http://www.springerlink.com/content/h104815q532202 80/abstract/.

49. Trier SC, Buckett JR, Campean A, Miller ME, Montague FW, Vrabec TL, et al, A modular external control unit for functional electrical stimulation. Proc. 6th Annu. Conf. Int. Funct. Electr. Stimul. Soc. [Internet]. 2001;312-4. Available from:https://www.researchgate.net/profile/Tina_Vrabec2/ publication/254766924_A_MODULAR_EXTERNAL_CONTROL_UNIT_FOR FUNCTIONAL_ELECTRICAL_STIMULATION/links/543fee1 c0cf2fd72f99 dc7e8/ AMODULAR-EXTERNAL-CONTROL-UNIT-FOR-FUNCTIONAL-ELECTRICALSTIMULATION.pdf. 
50. Bhadra N, Kilgore K, Peckham P. Implanted stimulators for restoration of function in spinal cord injury. Med Eng Phys. 2001;23:19-28 Available from: https://linkinghub.elsevier.com/retrieve/pii/S1350453301000121.

51. Smith B, Peckham PH, Keith MW, Roscoe DD. An Externally Powered, Multichannel, Implantable Stimulator for Versatile Control of Paralyzed Muscle. IEEE Trans Biomed Eng. 1987;BME-34:499-508 Available from: http:// ieeexplore.ieee.org/document/4122581/.

52. Smith B, Tang Z, Johnson MW, Pourmehdi S, Gazdik MM, Buckett JR, et al. An externally powered, multichannel, implantable stimulator-telemeter for control of paralyzed muscle. IEEE Trans Biomed Eng. 1998;45:463-75 Available from: http://ieeexplore.iee.org/document/664202/.

53. Gustafson KJ, Grinberg Y, Joseph S, Triolo RJ. Human distal sciatic nerve fascicular anatomy: implications for ankle control using nerve-cuff electrodes. J Rehabil Res Dev. 2012;49:309-21 [cited 2012 Sep 25]. Available from: http://www.ncbi.n/m.nih.gov/pubmed/22773531.

54. Matthews WB. Aids to the examination of the peripheral nervous system. J Neurol Sci. 1977;33:299.

55. Polasek KH, Schiefer MA, Pinault GCJ, Triolo RJ, Tyler DJ. Intraoperative evaluation of the spiral nerve cuff electrode on the femoral nerve trunk. J Neural Eng. 2009;6:066005 [cited 2012 Sep 25]. Available from: http://www. ncbi.nlm.nih.gov/pubmed/19901448.

56. Letechipia JE, Peckham PH, Gazdik M, Smith B. In-line lead connector for use with implanted neuroprosthesis. IEEE Trans Biomed Eng. 1991;38:707-9 [cited 2016 Nov 7]. Available from: http://www.ncbi.nlm.nih.gov/pubmed/1 879864.

57. Marsolais EB, Kobetic R. Implantation techniques and experience with percutaneous intramuscular electrodes in the lower extremities. J Rehabil Res Dev. 1986;23:1-8 [cited 2019 Sep 25]. Available from: http://www.ncbi. nlm.nih.gov/pubmed/3490566.

58. Memberg WD, Peckham PH, Thrope GB, Keith MW, Kicher TP. An analysis of the reliability of percutaneous intramuscular Electrodes in upper extremity FNS applications. IEEE Trans Rehabil Eng. 1993;1:126-32.

59. Stålberg E, Falck B, Gilai A, Jabre J, Sonoo M, Todnem K. Standards for quantification of EMG and neurography. The International Federation of Clinical Neurophysiology. Electroencephalogr Clin Neurophysiol Suppl. 1999; 52:213-20.

60. Preston DC, Shapiro BE. Electromyography and neuromuscular disorders: clinical-electrophysiological correlations. Philadelphia: Elsevier Saunders; 2013.

61. Butler K, Morris J, Scott KR, Simmons Z. Neuroanatomy for Nerve Conduction Studies 2010 Courses Neuroanatomy for Nerve Conduction Studies. Am. Assoc. Neuromuscul. Electrodiagn. Med. 57th Annu. Meet. [Internet]. 2010;1-36. Available from: https://www.abemexam.org/ getmedia/3b50a213-8b05-44c0-b9d5-7d42decf5b30/2-Coursebook Neuroanatomy-for-NCS-CNCT-studymaterial2.pdf.

62. Chiodo A, Spiegelberg T, Tong HC. Comparing saphenous Nerve conduction study techniques at the knee and at the ankle and their relationship to body mass index. Arch Phys Med Rehabil. 2007:88:477-80.

63. Wu PB, Gussner CG, Date ES. Correlation of EMG, CMAP and SNAP amplitude decrease in mononeuropathies with axonal loss. Electromyogr Clin Neurophysiol. 1996:36:405-9 [cited 2017 Jul 29]. Available from: http:// www.ncbi.nlm.nih.gov/pubmed/8957165.

64. Davis JA, Triolo RJ, Uhlir JP, Bhadra N, Lissy DA, Nandurkar S, et al. Surgical technique for installing an eight-channel neuroprosthesis for standing. Clin Orthop Relat Res. 2001:237-52 [cited 2016 Apr 22]. Available from: http:// www.ncbi.nlm.nih.gov/pubmed/11302320.

65. Shannon RV. A model of safe levels for electrical stimulation. IEEE Trans Biomed Eng. 1992;39:424-6 Available from: http://ieeexplore.ieee.org/ document/126616/.

66. Merrill DR, Bikson M, Jefferys JGR. Electrical stimulation of excitable tissue: design of efficacious and safe protocols. J Neurosci Methods. 2005;141:17198 Available from: http://www.ncbi.nlm.nih.gov/pubmed/15661300.

67. McCreery DB, Agnew WF, Yuen TGH, Bullara L. Charge density and charge per phase as cofactors in neural injury induced by electrical stimulation. IEEE Trans Biomed Eng. 1990;37:996-1001 Available from: http://ieeexplore. ieee.org/document/102812/\%0Apapers3://publication/uuid/DAE99EA980E8-4FA1-A763-6754AFAE10D5.

68. Günter C, Delbeke J, Ortiz-Catalan M. Safety of long-term electrica peripheral nerve stimulation: review of the state of the art. J Neuroeng Rehabil J Neuro Eng Rehabil. 2019;16:1-16.
69. Schiefer MA, Freeberg M, Pinault GJC, Anderson J, Hoyen H, Tyler DJ, et al. Selective activation of the human tibial and common peroneal nerves with a flat interface nerve electrode. J Neural Eng. 2013;10:056006 Available from: http://www.pubmedcentral.nih.gov/articlerender.fcgi?artid=3809099\&tool= pmcentrez\&rendertype=abstract.

70. Katz B, Miledi R. The Measurement of Synaptic Delay, and the Time Course of Acetylcholine Release at the Neuromuscular Junction. Proc R Soc London B Biol Sci. 1965;161 [cited 2017 Jul 24]. Available from: http://rspb. royalsocietypublishing.org/content/161/985/483.

71. Katz B, Miledi R. The effect of temperature on the synaptic delay at the neuromuscular junction. J Physiol. 1965;181:656-70.

72. Wongsarnpigoon A, Woock JP, Grill WM. Efficiency analysis of waveform shape for electrical excitation of nerve fibers. IEEE Trans Neural Syst Rehabil Eng. 2010;18:319-28 NIH Public Access. [cited 2017 Jan 22]. Available from: http://www.ncbi.nlm.nih.gov/pubmed/20388602.

73. Mogyoros I, Kiernan MC, Burke D. Strength-duration properties of human peripheral nerve. Brain. 1996:119(Pt 2):439-47.

74. Sunderland S. Nerves and nerve injuries. London: Churchill Livingstone; 1978.

75. Fugleholm K, Schmalbruch H, Krarup C. Early peripheral nerve regeneration after crushing, sectioning, and freeze studied by implanted electrodes in the cat. J Neurosci. 1994;14:2659-73 Available from: http://www.ncbi.nlm. nih.gov/pubmed/8182434.

76. Jones EJ, Bishop PA, Woods AK, Green JM. Cross-sectional area and muscular strength: a brief review. Sports Med. 2008;38:987-94 [cited 2017 Sep 19]. Available from: http://www.ncbi.nlm.nih.gov/pubmed/19026016.

77. Maughan RJ, Watson JS, Weir J. Muscle strength and cross-sectional area in man: a comparison of strength-trained and untrained subjects. Br J Sports Med. 1984;18:149-57 Available from: http://ukpmc.ac.uk/abstract/MED/64 87941\%5Cn. http://www.pubmedcentral.nih.gov/articlerender.fcgi?artid=185 9378\&tool=pmcentrez\&rendertype=abstract.

78. Heaton JT, Kobler JB. Use of muscle fibrillation for tracking nerve regeneration. Muscle Nerve. 2005;31:235-41.

79. Ben-David B, Stahl S. Prognosis of intraoperative brachial plexus injury: a review of 22 cases. Br J Anaesth. 1997;79:440-5 [cited 2017 Jul 20]. Available from: http://www.ncbi.nlm.nih.gov/pubmed/9389259.

80. Triolo RJ, Bailey SN, Miller ME, Rohde LM, Anderson JS, Davis JA, et al. Longitudinal Performance of a Surgically Implanted Neuroprosthesis for Lower-Extremity Exercise, Standing, and Transfers After Spinal Cord Injury. Arch Phys Med Rehabil. 2012;93:896-904 [cited 2017 Jul 20]. Available from: http://linkinghub.elsevier.com/retrieve/pii/S0003999312000160.

81. Rodosky MW, Andriacchi TP, Andersson GBJ. The influence of chair height on lower limb mechanics during rising. J Orthop Res. 1989;7:266-71 [cited 2017 Jan 22]. Available from: http://www.ncbi.nlm.nih.gov/pubmed/291 8425 .

82. Kotake T, Dohi N, Kajiwara T, Sumi N, Koyama Y, Miura T. An analysis of sitto-stand movements. Arch Phys Med Rehabil. 1993;74:1095-9 [cited 2017 Jan 22]. Available from: http://www.ncbi.nlm.nih.gov/pubmed/8215863.

83. Uhlir JP, Triolo RJ, Kobetic R. The use of selective electrical stimulation of the quadriceps to improve standing function in paraplegia. IEEE Trans Rehabil Eng. 2000;8:514-22 [cited 2016 Apr 28]. Available from: http://www. ncbi.nlm.nih.gov/pubmed/11204043.

84. Kagaya H, Shimada Y, Ebata K, Sato M, Sato K, Yukawa T, et al. Restoration and analysis of standing-up in complete paraplegia utilizing functional electrical stimulation. Arch Phys Med Rehabil. 1995;76:876-81 [cited 2017 Jan 22]. Available from: http://www.ncbi.nlm.nih.gov/pubmed/7668962.

85. Tözeren A. Human body dynamics : classical mechanics and human movement. New York: Springer; 2000.

86. Clauser CE, McConville JT, Young JW. Weight, Volume, and Center of Mass of Segments of the Human Body [Internet]. 1st ed. Natl. Tech. Inf. Serv. Springfield, VA: National Tehnical Information Service. US Department of Commerce; 1969. Available from: https://pdfs.semanticscholar.org/8eda/33 ffe8e628c2d058d880e011c3c76c10604b.pdf.

87. Freeberg MJ, Ansari R, Pinault GCJ, Lombardo LM, Miller ME, Tyler DJ, et al. Intraoperative responses may predict chronic performance of composite flat Interface Nerve Electrodes on Human femoral nerves. IEEE Trans Neural Syst Rehabil Eng. 2019;27:2317-23278 Available from: https://ieeexplore.ieee.org/ document/8890669/.

88. Fisher LE. Improving Neuroprosthesis-Assisted Standing with Nerve-Based Stimulating Electrodes [Internet]: Case Western Reserve University; 2012. 
[cited 2017 May 1]. Available from: http://rave.ohiolink.edu/etdc/view?acc_ num $=$ case 1332536090 .

89. Kiernan MC. Effects of temperature on the excitability properties of human motor axons. Brain. 2001;124:816-25 Available from: https://academic.oup. com/brain/article-lookup/doi/10.1093/brain/124.4.816.

90. Lane D. Online Statistics Education. In: Lovric M, editor. Int. Encycl. Stat. Sci. Berlin, Heidelberg: Springer Berlin Heidelberg; 2011. p. 1018-20. Available from: https://doi.org/10.1007/978-3-642-04898-2_48.

91. Maathuis E, Henderson R, Drenthen J, Hutchinson N, Daube J, Blok J, et al. Optimal stimulation settings for CMAP scan registrations. J Brachial Plex Peripher Nerve Inj. 2014;07:e1-7 Available from: http://www.thieme-connect. de/DOI/DOI?10.1186/1749-7221-7-4.

92. Gerrits HL, De Haan A, Hopman MT, van Der Woude LH, Jones DA, Sargeant AJ. Contractile properties of the quadriceps muscle in individuals with spinal cord injury. Muscle Nerve. 1999;22:1249-56 Available from: http:// onlinelibrary.wiley.com/doi/10.1002/(SICI) 1097-4598(199909)22:9\%3C1249:: AID-MUS13\%3E3.0.CO;2-N/abstract\%5Cn. http://www.ncbi.nlm.nih.gov/ pubmed/10454722.

93. Meijer K, Bosch P, Bobbert MF, Van Soest AJ, Huijing PA. The isometric knee extension momentangle relationship: experimental data and predictions based on cadaver data. J Appl Biomech. 1998;14:62-79.

94. Hayashibe M, Zhang Q, Guiraud D, Fattal C. Evoked EMG-based torque prediction under muscle fatigue in implanted neural stimulation. J Neural Eng. 2011;8:064001.

\section{Publisher's Note}

Springer Nature remains neutral with regard to jurisdictional claims in published maps and institutional affiliations.

Ready to submit your research? Choose BMC and benefit from:

- fast, convenient online submission

- thorough peer review by experienced researchers in your field

- rapid publication on acceptance

- support for research data, including large and complex data types

- gold Open Access which fosters wider collaboration and increased citations

- maximum visibility for your research: over $100 \mathrm{M}$ website views per year

At $\mathrm{BMC}$, research is always in progress.

Learn more biomedcentral.com/submissions 